\title{
Rules of induction of labor, complication and benefits
}

\author{
Abdulaziz Abdullah Alhazmi, Mana Ali Mueidh Al hajlan, Abdullah Salem Al Haider, Yaqoub \\ Mubarak Ali Alhamami, Nasser Naji Mohsen Al Harthi, Mohammed Hundur Alasmari, \\ Alhussain Abdullah Jarullah Albudaydi
}

Najran University, Medical Collage

\begin{abstract}
Background: induction of labor is a usual obstetric method and it is applied when the benefits to either mother or fetus outweigh those of continuing the pregnancy. Objective: in this review we discussed the advantages and disadvantages and specifically mention about indications. Methodology: we searched MEDLINE and the Cochrane Library up to June 2018. Through our search we used multiple terms and combinations including labor, induced/or induction of labor. Result: for uterine hyperstimulation, double-balloon catheter had the highest probability of being among the best three treatments, whereas vaginal misoprostol $(\geq 50 \mu \mathrm{g})$ was most likely to increase the odds of excessive uterine activity. For other safety outcomes there were insufficient data or there was too much uncertainty to identify which treatments performed 'best'. Conclusion: elective IOL needs to only be done in rare or extraordinary circumstances, only when the mom has actually completed 39 weeks of pregnancy, and only when it would be beneficial to the mom and not cause damage to the newborn. Ladies with uncomplicated maternities must be given every opportunity to go into spontaneous labor. Women with uncomplicated pregnancies should typically be offered induction of labor in between 41 +0 and $42+0$ weeks to avoid the threats of prolonged pregnancy.
\end{abstract}

Key words: induction of labor, prolonged pregnancy, rules of induction of labor, complication, benefits

\section{Introduction}

Induction of labor is specified as the process of artificially promoting the uterus to start labor.8 Induction of labor (IOL) is a usual technique, increasing twofold over the last 10 years ${ }^{[1]}$. In 2000 around one in 5 births were induced in the United Kingdom, the United States and Canada $18 \%$ United Kingdom ${ }^{[2]}$, 20\% United States ${ }^{[3]}$, $19 \%$ Canada ${ }^{[4]}$. Hippocrates initially described methods for IOL via mammary stimulation and mechanical cervical extension [1]. From the second century ad forward, professionals have used methods such as synthetic rupture of membrane layers and manual expansion of the cervix ${ }^{[5]}$. Much more current advancements, consisting of drugs and mechanical devices, have actually supplied provider's significantly effective methods of inducing labor. Once thought about unthinkable, vaginal birth after caesarean (VBAC) has been actively promoted as a technique to reduce the climbing caesarean delivery $(\mathrm{CD})$ rates in the United Kingdom and also the United States. As induction of labor and VBAC prices increased, eligibility requirements broadened such that some ladies with prior caesarean were taken into consideration eligible for induction of labor. Current extremely publicized records of uterine rupture for women ${ }^{[5]}$ with prior caesarean undertaking trial of labor (TOL) and induction of labor in particular raised issues for the safety and security of the method of induction of labor in ladies with previous caesarean. The Royal College of Obstetricians and also Gynaecologists and the American College of Obstetricians and Gynecologists contradict regarding the safety of induction of labor, specifically with prostaglandins, for women with prior caesarean ${ }^{[6]}$. Induction of labor is a usual obstetric method and is applied when the benefits to either mother or fetus outweigh those of continuing the pregnancy. In this review we discuss the advantages and disadvantages, and specifically mention about indications.

\section{Methodology}

We searched MEDLINE and the Cochrane Library up to June 2018. Through our search we used multiple terms and combinations, including labor, induced/or induction of labor, we performed a best evidence review of the literature of published studies English with human subject. 
Table 1: definitions for gestational age categories ${ }^{[7]}$

\begin{tabular}{|l|l|}
\hline Definition & Description \\
\hline Late preterm & $340 / 7-366 / 7$ weeks \\
\hline Early term & $370 / 7-386 / 7$ weeks \\
\hline Full term & $390 / 7-406 / 7$ weeks \\
\hline Late term & $410 / 7-416 / 7$ weeks \\
\hline Post term & $420 / 7$ weeks \\
\hline
\end{tabular}

Table 2: selected pregnancy conditions and recommended timing of birth for late preterm and early term births ${ }^{[6]}$

\begin{tabular}{|c|c|}
\hline Pregnancy Condition & $\begin{array}{l}\text { Recommended } \\
\text { Gestational Age at } \\
\text { Which Birth Should } \\
\text { Occur }\end{array}$ \\
\hline $\begin{array}{lr}\begin{array}{l}\text { Growth } \\
\text { singleton, } \\
\text { uncomplicated }\end{array} & \begin{array}{r}\text { restriction, } \\
\text { otherwise }\end{array} \\
\end{array}$ & 38 0/7-39 6/7 weeks \\
\hline $\begin{array}{l}\text { Growth restriction, } \\
\text { singleton, } \\
\text { oligohydramnios, } \\
\text { abnormal Doppler studies, } \\
\text { or maternal comorbidity }\end{array}$ & 34 0/7-37 6/7 weeks \\
\hline Oligohydramnios & 36 0/7-37 6/7 weeks \\
\hline Twins: di-di & 38 0/7-38 6/7 weeks \\
\hline Twins: mono-di & 34 0/7-37 6/7 weeks \\
\hline $\begin{array}{l}\text { Gestational diabetes well } \\
\text { controlled on diet or } \\
\text { medications }\end{array}$ & Early birth not indicated \\
\hline $\begin{array}{ll}\text { Gestational } \\
\text { uncontrolled }\end{array}$ & $\begin{array}{l}\text { Individualized } \\
\text { management }\end{array}$ \\
\hline $\begin{array}{ll}\begin{array}{l}\text { Pregestational diabetes } \\
\text { well controlled }\end{array} & \\
\end{array}$ & Early birth not indicated \\
\hline $\begin{array}{l}\text { Pregestational diabetes } \\
\text { uncontrolled }\end{array}$ & $\begin{array}{ll}\text { Early birth } \\
\text { individualized }\end{array}$ \\
\hline $\begin{array}{lr}\begin{array}{l}\text { Growth } \\
\text { singleton, } \\
\text { uncomplicated }\end{array} & \begin{array}{r}\text { restriction, } \\
\text { otherwise }\end{array} \\
\end{array}$ & 38 0/7-39 6/7 weeks \\
\hline $\begin{array}{ll}\begin{array}{l}\text { Pregestational } \\
\text { with }\end{array} & \text { diabetes } \\
\text { complications } & \text { vascular } \\
\end{array}$ & 37 0/7-39 6/7 weeks \\
\hline Placenta previa & 36 0/7-37 6/7 weeks \\
\hline $\begin{array}{l}\text { Placenta previa with } \\
\text { suspicion for percreta, } \\
\text { accreta, or increta }\end{array}$ & 34 0/7-35 6/7 weeks \\
\hline $\begin{array}{lll}\begin{array}{l}\text { History } \\
\text { cesarean }\end{array} & \text { of classical } \\
\end{array}$ & 36 0/7-37 6/7 weeks \\
\hline History of myomectomy & 37 0/7-38 6/7 weeks \\
\hline
\end{tabular}

Abbreviations: ACOG, American College of Obstetricians and Gynecologists; di-di, dichorionic and diamnionic; mono-di, monochorionic and diamniotic.

Table 3: indications requiring immediate induction ${ }^{[13-14]}$

\footnotetext{
1.Suspected fetal compromise

Biophysical profile score less than or equal to 4

Oligohydramnios (Amniotic Fluid Index (AFI) less than 5)

2.Intrauterine growth restriction with evidence of compromise

Growth curve less than 3rd percentile

Serial ultrasounds showing lack of growth
}

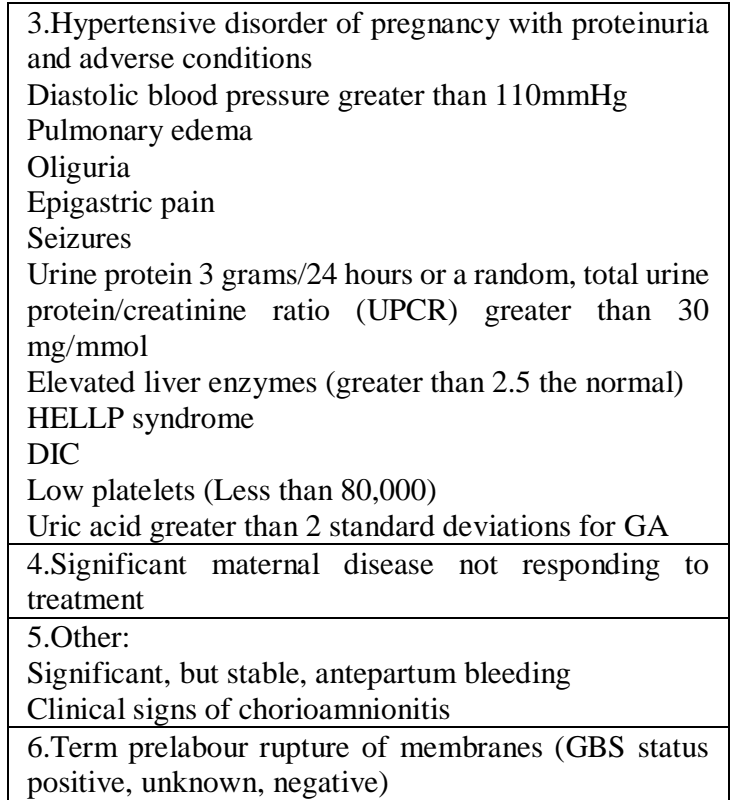

Table 4: guide for shared decision making on induction of labor ${ }^{[12]}$

\begin{tabular}{|c|c|}
\hline Indication & $\begin{array}{l}\text { Include diagnostic criteria } \\
\text { for medical indication, } \\
\text { dating criteria for } \\
\text { gestational age, and time } \\
\text { frame }\end{array}$ \\
\hline Risks to woman & $\begin{array}{l}\text { Risks associated with } \\
\text { medical indication for not } \\
\text { giving birth: } \\
\text { Varies depending on } \\
\text { medical indication } \\
\text { Risks associated with } \\
\text { IOL: } \\
\text { Higher risk for cesarean } \\
\text { in nulliparous women } \\
\text { with an unfavorable } \\
\text { cervix for } \\
\text { Possible need for } \\
\text { increased interventions: } \\
\text { fetal scalp electrode, } \\
\text { intrauterine pressure } \\
\text { catheter, artificial rupture } \\
\text { of membranes } \\
\text { Side effects of } \\
\text { medications } \\
\text { unintended and } \\
\text { reactions adverse } \\
\text { Longer labors } \\
\text { Postpartum hemorrhage } \\
\text { Infection } \\
\text { Failed IOL }\end{array}$ \\
\hline Risks to fetus & $\begin{array}{l}\text { Fetal intolerance of labor } \\
\text { Infection } \\
\text { Respiratory distress } \\
\text { syndrome }\end{array}$ \\
\hline $\begin{array}{ll}\text { Medication } & \text { options: } \\
\text { risks and } & \text { relative } \\
\text { effectiveness } & \end{array}$ & $\begin{array}{l}\text { Include medications } \\
\text { commonly used for IOL, } \\
\text { when used, and relative } \\
\text { effectiveness of each }\end{array}$ \\
\hline Restrictions during IOL & $\begin{array}{l}\text { Food/drink, monitoring } \\
\text { per hospital policy, use of } \\
\text { tub for hydrotherapy and }\end{array}$ \\
\hline
\end{tabular}




\begin{tabular}{|l|l|}
\hline & $\begin{array}{l}\text { water birth per hospital } \\
\text { policy, visitor policy }\end{array}$ \\
\hline Logistics & $\begin{array}{l}\text { Date and time of IOL, } \\
\text { location, parking, } \\
\text { preparation before (eat } \\
\text { breakfast, shower) }\end{array}$ \\
\hline
\end{tabular}

Discussion:

- Benefits and requirement for induction of Labor

A pregnant female is 'at term' when her maternity period gets to 37 weeks (Table 1). Approximately $10 \%$ of pregnancies continue beyond 294 days (420/7 weeks) and also are referred to as being 'post-term' or 'postdate', although this can differ noticeably between nations ${ }^{[7]}$.

While, the aetiology of post-term birth is not well clarified ${ }^{[7]}$, risk factors such as obesity, nulliparity as well as mother's age more than 30 years have actually been related to a raised threat of post-term birth. Placental senescence might contribute in the pathophysiology of post-term birth ${ }^{[7]}$.Both the mommy and the baby are at increased threat of damaging occasions when the maternity continues past term. Hilder reported the risk of fetal or infant losing per 1000 continuous maternities past term ${ }^{[8]}$. After 41 weeks, neonatal as well as postneonatal fatality threat raised substantially.

Olesen et al. carried out a cross-sectional research study of birth registry data between 1978 to 1993 in Denmark ${ }^{[9]}$ and showed comparable outcomes, that was, substantial rise in perinatal fatality and also morbidities. The majority of post-term births occurred at 42 weeks $(87 \%)$ while, less than $1 \%$ of ladies delivered at 44 weeks or later on. The overall risk of perinatal fatality was $0.4 \%$ in the postterm group and also $0.3 \%$ in the term team in Olesen $\boldsymbol{e t}$ al. study. In a later research, reported by the Norwegian Birth Registry ${ }^{[10]}$, the perinatal death rate was $0.018 \%$ at day 287 as well as $0.51 \%$ at day $302+$. These study is necessary in setting where early reservation enables exact evaluation of gestational age as well as antenatal solutions are accessible for a lot of ladies, post-term maternity makes up a risky circumstance, particularly for the child.The obstetric troubles related to post-term pregnancy consist of induction of labor with an undesirable cervix, caesarean section, extended labor, postpartum hemorrhage and terrible birth. It is most likely that a few of these undesirable outcomes arise from intervening when the womb and cervix are not prepared for
labor.Early pregnancy ultrasound is associated with a reduced occurrence of post-term maternity perhaps by preventing misclassification ${ }^{[9,10]}$. Induction of labor is commonly practiced to try and also avoid the troubles discussed over as well as improve the wellness result for females as well as their babies. Unfortunately, labor induction may itself cause problems particularly when the cervix is not beneficial. Furthermore, the excellent timing for induction of labor is unclear. In the past, there was a tendency to wait for spontaneous labor until 42 finished weeks. Crowley ${ }^{[11]}$ suggested that induction of labor at or from 41 weeks lowered perinatal death without increasing caesarean area and also other damaging results. Various other writers have actually wrapped up that labor induction at 41 weeks or more is connected with a lowered caesarean section rate as well as no distinction in perinatal death [7-10]. Earlier researches have actually likewise considered treatments prior to the post-term phase is attained.The gestational age as well as cervix being unfavorable could impact the effectiveness of the induction of labor as well as the resulting caesarean section rates. When the cervix is favorable (normally a Bishop score of six or more), induction is frequently carried out by oxytocin as well as unnatural tear of amniotic membranes. If the cervix is not favorable after that usually a prostaglandin gel or tablet is put in the vagina or cervix to ripen the cervix and initiate the uterine contractions and labor. Many protocols are applied with varying repeat intervals and transition to oxytocin and amniotomy relying on the beginning of uterine contractions as well as development of cervical dilatation. The patient must fully recognize the threats and positive aspects associated with the choice to induce labor. The primary health care specialist should assure that the threats associated with induction outbalance the risks of waiting for spontaneous labor to ensue. The discussion between the primary health care practitioner and also the patient when it comes to risks and benefits of induction must be recorded. Accepted parameters for seriousness of induction in the Edmonton zone are listed below. These criteria are based on risk decrease and the need to chase best outcomes for mommies and also infants [13].

How is labor induced ${ }^{[10-12]}$ ?

Labor can be induced by: 
- breaking the bag of waters

- giving intravenous (IV) drugs (for example oxytocin)

- inserting medications into the vagina or cervix

- RISKS of INDUCTION of LABOR

Concerns about the safety and security for ladies and also newborns secondary to IOL include the effects of excessive uterine activity; a prospective rise in the rate of cesarean; boosted threat for postpartum hemorrhage $(\mathrm{PPH})$; as well as negative effects on the newborn such as fetal intolerance of labor, infection, as well as respiratory distress syndrome. There is a considerable body of literature regarding damaging perinatal outcomes related to IOL; nonetheless, it is commonly difficult to differentiate causation from organization due to the methodological weak points of existing research ${ }^{[12]}$.

\section{Tachysystole}

Excessive uterine activity could happen during spontaneous or induced labor and with any of the pharmacologic methods utilized for IOL. Recently, professional interdisciplinary panels have actually sought to clarify terms pertaining to excessive uterine activity, specifying uterine tachysystole as the preferred term ${ }^{[15]}$ Results of tachysystole for the fetus can consist of hypoxia, acidemia, acidosis, brain damage, or fatality if the tachysystole persists uncorrected. Fetuses at raised risk for acidemia additional to growth limitation, infection, or other issues are specifically susceptible. Uterine tear, although rare, is a feasible maternal problem of tachysystole. In one study of women whose labors were being caused with oxytocin (Pitocin), 98\% demonstrated at least one occurrence of tachysystole ${ }^{[16]}$.

\section{Induction of Labor and Cesarean}

Enhanced prices of cesarean have regularly been cited as an undesirable impact of IOL, however the evidence for a causal relationship doubts since in many cases the same conditions for which IOL is indicated could separately boost the possibility of cesarean. Study findings on the dangers related to clinically shown IOL vary from the research findings of risks associated with elective IOL. In one huge retrospective cohort of nulliparous women at term that had a singleton unborn child in a vertex presentation $(\mathrm{N}=7804)$ with numerous medical signs for birth, the overall odds ratio (OR) for cesarean was 2 times better for those whose labors were induced (OR, 2.67; 95\% CI, 2.40-2.96), with IOL accounting for $20 \%$ of the total cesarean danger ${ }^{[17]}$. The odds of cesarean in the ladies in this analysis that did not have medical issues and also whose labors were electively caused was 2.03 (95\% CI, 1.732.38). Other research studies excluding females with complications for which IOL was suggested showed contrary findings. A retrospective contrast of optional IOL versus expecting management at various term gestational ages located that at each gestational age, the OR for cesarean complying with elective IOL had to do with one-half that of expectant management ${ }^{[18]}$. Two methodical testimonials of randomized trials that contrasted expectant management to IOL discovered a reduced rate of cesarean among those whose labor was induced, with ORs of 0.83 (95\% CI, 0.76-0.92) and 0.87 (95\% CI, $0.80-0.96)^{[19]}$ respectively. Due to the fact that these studies just consisted of ladies who were possibly candidates for expectant management, they could give an extra accurate photo of the contribution of IOL to the threat of cesarean. Various other research studies ${ }^{[12,13,14]}$ have actually revealed that a woman's risk of unsuccessful IOL and/or cesarean may be raised by individual aspects such as nulliparity, low Bishop score, high body mass index, and diabetic issues.

\section{Postpartum Hemorrhage}

Proof regarding the danger of PPH amongst women whose labor is induced is limited. Malabarey et al found that prostaglandins however not oxytocin were connected with an increased danger of PPH ${ }^{[20]}$. One methodical review ended that there is not sufficient evidence to identify whether IOL enhances the threat of PPH.

\section{Effects on the Newborn}

Just recently, problems for newborn difficulties arising from IOL have actually focused on gestational age at the time of birth morbidity and death are both greater for babies born before 39 finished weeks gestation. Neonatal death was higher at 37 weeks (OR, 1.9; $95 \% \mathrm{CI}$, 1.6-2.2) as well as 38 weeks (OR, 1.4; 95\% CI, 1.2-1.6) compared to 39 weeks pregnancy ${ }^{[24]}$. Morbidity is also significantly higher for babies before 39 weeks pregnancy. Birth in between 37 as well as 39 weeks gestation is related to a 2 times higher rate of neonatal intensive care unit (NICU) admission ${ }^{[18]}$. In one retrospective mate, elective IOL accounted for a disproportionate share of NICU admissions; optional IOL stood for $32 \%$ of the example yet 
$40.9 \%$ of NICU admissions ${ }^{[21]}$. Infants birthed at 37 weeks' pregnancy are also at greater danger for respiratory system distress syndrome (OR, 3.1; 95\% CI, 2.5-3.7) than those birthed after 39 weeks gestation [22]. Additional enhanced dangers include sepsis, short-term tachypnea of the newborn, pneumonia, ventilator use, hypoglycemia, cerebral palsy, as well as developmental hold-ups. When matched for gestational age, newborn outcomes seem similar for ladies managed expectantly and also those who have optional IOL. A methodical review discovered no differences in the rates of transient tachypnea of the newborn, neonatal sepsis, seizures, hypoglycemia, jaundice or lowered Apgar scores ${ }^{[25]}$.A current epidemiologic research study increased new concerns about IOL and the danger of autism [23]. After controlling for some prospective confounders, those authors discovered that IOL was associated with an increased risk of autism (OR, 1.23; 95\% CI, 1.02-1.47), which was greater amongst male offspring (OR, 3.04; 95\% CI, 2.86-3.24) ${ }^{[23]}$. Mentioning evidence of the impact of oxytocin on social and also cognitive features, the authors hypothesized that the prevalent use oxytocin for IOL can represent the observed distinction in rates of autism ${ }^{[23]}$. Since the evaluation did not compare elective and showed IOL, and because data were not available for all feasible confounders, it is feasible that the enhanced autism risk could be attributable to the existence of maternal problems for which IOL was indicated. In conclusion, it is difficult to distinguish between the dangers of IOL per se and also the risks connected with early birth with the problems for which IOL may be clinically indicated. Based upon exactly what is found out about the dangers of IOL, it showed that in the presence of maternal or fetal problems it was understood to raise the dangers of proceeding pregnancy, the dangers of IOL are limited and/or convenient. In the lack of such conditions, it is more difficult to validate unnecessary direct exposure to the risks of IOL, even when the proof for these dangers is incomplete or inconsistent.

\section{Conclusion}

Elective IOL needs to only be done in rare or extraordinary circumstances, only when the mom has actually completed 39 weeks of pregnancy, and only when it would be beneficial to the mom and not cause damage to the newborn. Ladies with uncomplicated maternities must be given every opportunity to go into spontaneous labor. Women with uncomplicated pregnancies should typically be offered induction of labor in between $41+0$ and $42+0$ weeks to avoid the threats of prolonged pregnancy. The precise timing should take into account the female's choices as well as local conditions. If a female chooses not to have induction of labor, her decision should be valued. Health care specialists ought to discuss the woman's care with her after that. From 42 weeks, women who decline induction of labor need to be provided enhanced antenatal monitoring containing at the very least twiceweekly cardiotocography as well as ultrasound evaluation of maximum amniotic pool depth.

\section{References}

1. Zhang J, Klebanoff MA and DerSimonian R (1999): Epidural analgesia in association with duration of labor and mode of delivery: a quantitative review. Am. J. Obstet. Gynecol., 180(4):970-977.

2. Thomas $J$ and Paranjothy $S$ (2001): National Sentinel Caesarean Section Audit Report. Royal College of Obstetricians and Gynecologists Clinical Effectiveness Support Unit. RCOG Press, London.

3. Curtin SC and Martin JA (2000): Births: preliminary data for 1999 . Natl. Vital Stat. Rep., 48(14):1-20.

4. Public Health Agency of Canada, Canadian Perinatal Surveillance System (2000): Health services cesarean section rate. Canadian Perinatal Report 2000. Ottawa, Canada: Minister of Public Works and Government Services. Doi: publications.gc.ca/site/eng/9.506795/p ublication.html

5. Lydon-Rochelle M, Holt VL, Easterling TR et al. (2001): Risk of uterine rupture during labor among women with a prior cesarean delivery. N. Engl. J. Med., 345(1):3-8.

6. Royal College of Obstetricians and Gynaecologists, Clinical Effectiveness Support Unit (2001): The use and interpretation of cardiotocography in intrapartum fetal 
surveillance. doi: 1424 RCOG Electronic Monitoring

7. Spong C (2013): Defining "term" pregnancy: Recommendations from the defining "term" pregnancy workgroup. JAMA., 309(23):2445- 2446.

8. Hilder $L$, Costeloe $K$ and Thilaganathan B(1998):Prolonged pregnancy: evaluating gestationspecific risks of fetal and infant mortality. British Journal of Obstetrics and Gynaecology, 105:169-173.

9. Olesen AW, Westergaard JG, Olsen J (2003): Perinatal and maternal complications related to postterm delivery: a national register-based study, 1978-1993. American Journal of Obstetrics and Gynecology, 189:222227.

10. Heimstad R, Romundstad PR, Salvesen KA (2008): Induction of labour for post-term pregnancy and risk estimates for intrauterine and perinatal death. Acta Obstetricia et Gynecologica, 87:247-9.

11. Crowley $P$ (2006): Interventions for preventing or improving the outcome of delivery at or beyond term. DOI: 10.1002/14651858.CD000170.pub2.

12. Moore JE, Kane L, Titler MG et al. (2014): Moving toward patientcentered care: Women's decisions, perceptions, and experiences of the induction of labor process. Birth, 41(2):138-146.

13. Wing Deborah A (2012): Principles of labor induction. sinalib.ir/uptodate/contents/mobiprevi ew.htm?30/37/31322?source=see_lin

14. National Institute for Health and Clinical Excellence (2008): Induction of Labour, 2nd ed., NICE Clinical Guideline. London, UK. RCOG Press.

15. Macones GA, Hankins GD, Spong CY et al. (2008): The 2008 National Institute of Child Health and Human Development Research workshop report on electronic fetal heart rate monitoring.

Obsetet Gynecol.,112(3):661-666.

16. Kunz MK, Loftus RJ, Nichols AA (2012): Incidence of uterine tachysystole in women induced with oxytocin. J Obstet Gynecol Neonatal Nurs., 42(1):12-18.

17. Ehrenthal DB, Jiang $X$, Strobino DM (2010): Labor induction and the risk of a cesarean delivery among nulliparous women at term. Obstet Gynecol.,116(1):35-42.

18. Darney BG, Snowden JM, Cheng YW et al. (2013): Elective induction of labor at term compared with expectant management: Maternal and neonatal outcomes. Obstet Gynecol., 122(4):761-769.

19. Wennerholm UB, Hagberg $H$, Brorsson B et al. (2013): Induction of labor versus expectant management for post-date pregnancy: is there sufficient evidence for a change in clinical practice? Acta Obstet Gynecol Scand., 88(1):6-17.

20. Malabarey O, Almog B, Brown R et al. (2011): Postpartum hemorrhage in low risk population. $\mathrm{J}$ Perinat Med.,39(5):495- 498.

21. Hoffmire C, Chess P, Saad TB et al. (2012): Elective delivery before 39 weeks: The risk of infant admission to the neonatal intensive care unit. MCHJ., 16(5):1053-1062.

22. Hibbard JU, Wilkins I, Sun L et al. (2010): The consortium on safe labor: Respiratory morbidity in late preterm births. JAMA., 304(4):419-425.

23. Gregory SG, Anthopolos R, Osgood CE et al. (2013): Association of autism with induced or augmented childbirth in North Carolina birth record (19901998) and education research (19972007) databases. JAMA Pediatr.,167(10):959-966.

24. Donovan EF, Besl J, Paulson J et al. (2010): Infant death among Ohio resident infants born at 32 to 41 weeks of gestation. Am J Obstet Gynecol., 203(1):58.e1-58.e5.

25. Caughey AB, Sundaram V, Kaimal AJ et al. (2009): Maternal and neonatal outcomes of elective induction of labor. https://www.ncbi.nlm.nih.gov/pubmed /19408970 